\title{
Analyzing the Antecedents of Organizational Ambidexterity from the Perspective of TMT and Firm Characteristics
}

\author{
Hang $W U^{1, a,{ }^{*}}$ \\ ${ }^{1}$ Business School, East China University of Political Science and Law, Shanghai \\ 201620, China \\ awuhang0503@163.com
}

Keywords: Organizational ambidexterity, TMT characteristics, Firm characteristics.

\begin{abstract}
Organizational ambidexterity is an important strategy for firm's survival. Existing research has discovered that TMT and firm characteristics are two influencing factors of organizational ambidexterity. TMT behavioral integration balances strategic conflicts between exploration and exploitation through creating a paradigmatic cognitive framework and processes. TMT diversification creates contradictory cognitive frameworks that can enhance the team's strategic planning capabilities and finally promote organizational ambidexterity. Except that, organizational ambidexterity can also be influenced by organizational foresight, learning capability and innovative culture. Innovative culture can help firms obtain strategic flexibility to adapt to the environment, and further help firms adjust their organizational practices to conflicts originating from ambidexterity.
\end{abstract}

\section{Introduction}

Researchers in strategic management field has highlighted that organizational ambidexterity is significantly important for firm's survival, which has attracted big discussion about the antecedents of organizational ambidexterity. The research on the influence factors of organizational ambidexterity can be divided into two aspects. On the one hand, scholars mainly answer the question of how to realize the ambidexterity of organization, which puts forward three methods to promote the ambidexterity of organization, namely structure ambidexterity, context ambidexterity, TMT characteristic. On the other hand, the scholars mainly answer the question of how organization ambidexterity is influenced by firm characteristics, including resource, capability and strategic orientation.

\section{TMT Characteristics}

It is noteworthy that both proponents of structural ambidexterity and context ambidexterity argue that executives play an indirect but important role in achieving organizational ambidexterity. For example, the dual structure within the same organization is easy to form the battle between the business units, thus enhancing the integration difficulty among different business units. Therefore, strategic integration is critical for achieving organizational ambidexterity. Researchers described these complex strategic integration processes and argued that it was important to carry out strategic debates within the organization and that executives should encourage opponents to dare to present their views. As a result, while there are inconsistencies in the integration of different business units within the organization, executives can drive the integration process. Similarly, setting up a high-performance behavioral scenario 
requires senior executives to guide resource access transparency, operational autonomy, decision-making equity and impartiality. Based on this logic, scholars have studied TMT characteristics, leadership behavior and organizational relationship between the ambidexterity of the study.

\section{TMT Behavioral Integration}

Smith and Tushman [1], for example, argue that creating a paradigmatic cognitive framework and processes in executives can help firms balance strategic conflicts between exploration and exploitation of activities. Lubatkin et al. [2] argue that by establishing a cohesive executive team that reflects the level of co-operative behavior of the executive team, the amount and quality of team communication, and the degree of emphasis on co-decision making, executives are open and free to communicate the differential knowledge, promote cooperation and joint decision-making within the executive team, and thus promote organizational ambidexterity. Carmeli and Halevi [3] further point out that the behavioral integration of executive team influences the organizational ambidexterity by influencing the complexity of team behavior. Behavioral complexity consists of two elements: behavior set, behavioral differentiation. Behavior sets represent the types of management roles that managers can perform, and behavior differentiation represents the manager's ability to adjust leadership roles based on organizational context. As a result, a cohesive and resource-sharing climate within the behavioral integration team enables leaders to use complementary resources to perform multiple leadership roles (behavioral set) while choosing the right leadership role to best respond to external environmental needs (behavioral differentiation), and thus promote the enterprise to carry out exploration and utilization activities.

Jansen et al. [4] argue that while structural dualism helps firms overcome the rigidities associated with organizational ambidexterity activities, it also poses a challenge to how corporate executives engage in resource allocation and knowledge integration. Jansen et al. [4] further pointed out that shared vision, social integration, contingency incentives of executive team have a positive impact on organizational ambidexterity. Building common goals and values within a dualistic organization can facilitate the exchange and integration of business units to explore and exploit, and team members are more likely to consider and accept disagreements on sensitive issues. The social integration mechanism within the team refers to the emotional factors between the team members, which can promote the compromise and collaboration between team members, and the desire for collective sense of honor, which can promote information exchange between team members to solve contradiction in the implementation of exploration and using activities. Contingency incentive reflects the correlation between team members benefits and team outcomes, which makes team members' interests above individual interests, reduces competition among individuals, and promotes negotiation and mutual adjustment, and are necessary for the simultaneous implementation of exploration and utilization activities.

\section{TMT Diversification}

Li [5] highlighted the strategic importance of executive team diversification for organizational ambidexterity. Diversification of executive teams can create contradictory cognitive frameworks that can enhance the team's strategic planning capabilities, which means that executives are more able to identify the different effects of exploration and exploitation, and thus promote the realization of organizational 
ambidexterity. In addition, the diversification of executive team will lead to the occurrence of internal conflicts within the team, and thus hinder the realization of organizational ambidexterity. $\mathrm{Li}$ [5] also found that the integration of senior management team will also improve the strategic planning capabilities, reduce interpersonal conflicts and contradictions within the team.

\section{TMT Leadership}

Nemanicha and Verab [6] argue that transformational leadership has a direct positive impact on organizational ambidexterity, and that transformational leadership is positively impacting organizational ambidexterity through a learning culture. Transformational leadership creates subordinate trust and follow-up by setting up an idealized image, giving direction to the subordinates to work hard, stimulating innovative behaviors of subordinates, providing humanistic care for subordinate personal development, and creating an environment that encourages cooperation, resource sharing and creativity, and thus promote the ambidexterity of the organization. In addition, transformational leadership can create a psychological security environment in which leaders take the opportunity to acknowledge and openly discuss their shortcomings, encourage team members to present diverse perspectives and participate in team decision making, resulting in an openness and free learning culture within the team, which makes it possible to carry out exploration and utilization activities at the same time.

Cao et al. [7] argue that SME leaders play a crucial role in the implementation of organizational ambidexterity strategy. Compared with large enterprises, SMEs do not have enough redundant resources and hierarchical management system, so SMEs need to rely on the executive capacity of the leaders to deal with a large number of contradictory information and knowledge process, and then to achieve organizational ambidexterity. CEOs with rich personal networks are able to access a wide range of information about their internal and external environments in a timely manner, thereby enabling the CEO to gain a deeper understanding of the options for exploration and exploitation, and avoid following any strategy without destination. In contrast, CEOs with poorly connected network are limited by access to information, making a biased exploration or strategic choice based solely on a particular function. The impact of the information superiority of the CEO's personal network on organizational ambidexterity relies on the level of information sharing (communication richness), overall assessment and understanding (complementarity), and common utilization (decentralization) between CEOs and TMT members.

\section{Firm Characteristics}

\section{Resource or Capability Perspective}

From the perspective of organizational learning theory, organizational ambidexterity can be understood as the simultaneous implementation of exploratory and exploitative innovation strategies. Therefore, in order to implement the dual innovation strategy at the same time, enterprises need to continuously monitor the external environment, obtain new knowledge from the outside, and also need to be able to integrate the knowledge into existing business areas. Organizational foresight is therefore the ability to explore and exploit external opportunities ${ }^{[8]}$, which requires organizations to search for, process and integrate knowledge from outside. Paliokaitè and Pačèsa [8] examined 
the impact of organizational foresight (environmental scanning ability, strategic choice ability, integration ability) on organizational ambidexterity by using 230 manufacturing enterprises as samples. The results show that environmental scanning ability, strategic choice ability and integration ability have positive effects on organizational ambidexterity (explorative innovation and exploitative innovation). Judge and Blocker [9] also suggest that implementing strategic ambidexterity requires a dynamic capability, namely organizational change capability, which refers to the ability of an organization to continually update its capabilities and create new capabilities to respond to new threats.

Lin et al. [10] selected 214 Taiwanese strategic business units as the analysis objects based on the view of resources theory, and testified the influence of learning ability on organizational ambidexterity (radical innovation and incremental innovation). Lin et al. [10] argue that a firm's ability to implement both radical and incremental innovation requires specific learning skills. Learning ability is defined as a set of business practices that promote employee learning within the organization, establish partnerships with other organizations (promoting learning diffusion), and open culture (promoting and sustaining knowledge sharing). The study found that when organizational learning, the establishment of external partnerships, open organizational culture together, the organization will have a positive impact on the ambidexterity.

\section{Strategic Perspective}

Zhang et al. [11] focused on the impact of entrepreneurial orientation and competency-based human resource management on innovation ambidexterity. Entrepreneurial orientation is a strategic attitude that reflects innovation, initiative and risk-taking. It also refers to a series of decision-making activities for enterprises to explore and exploit new market opportunities. Specifically, innovation refers to the creation of new ideas, support creativity and novelty, tendencies and capabilities to develop new products and processes. Initiative indicates that companies are involved in anticipating future market demands and leading their competitors to introduce new products or services. Risk-taking represents the willingness of firms to venture into the unknown and invest significant resources in uncertain R \& D activities. According to the definition of entrepreneurial orientation, entrepreneurial-oriented activities include an activity that effectively generates new market opportunities and integrates existing resources to take advantage of opportunities. In other words, entrepreneurial orientation helps companies achieve a balance between opportunity search (exploration) and advantage search (exploitation). Therefore, entrepreneurship-oriented enterprises are more likely to implement explorative and exploitative innovation, because companies can better adapt to and shape the environment. If firms only focus on exploration activities and ignore exploitation activities, then they will take on high risk and high input in innovation activities, reduce the benefits in using existing capacity. Conversely, focusing solely on exploitation activities may result in short-term gains but loss of future development opportunities.

Competency-based human resource management refers to a range of people management strategies and activities that enable employees to develop skills and knowledge that ultimately enhance competitive advantage. Competency-based human resource management promotes organizational ambidexterity mainly from three areas, namely the staff recruitment and selection, participation, learning mechanisms. First, in order to develop an organizational structure that supports ambidexterity, competency-based recruitment practices select employees and enable employees to 
explore new knowledge and improve existing knowledge by training. Second, competency-based participatory planning, such as teamwork, autonomy in work processes, regular team meetings, and proposed programs, allows members to spend their energies on the direction of accomplishing their goals, thereby facilitating the implementation of corporate strategic activities. The strengthening of employee autonomy allows employees to be more motivated to engage in exploration and utilization activities.

In addition, entrepreneurial orientation will interact with competency-based human resource management to influence innovation. Entrepreneurial orientation affects the way of firms to discover and exploit opportunities. Based on this view, entrepreneurship-oriented enterprises are more likely to integrate entrepreneurial thinking and competency-based human resource management to create an organizational structure in an additional way that allows employees to expand their knowledge and skills in the direction of explorative and exploitative innovation. Entrepreneurial orientation and competency-based human resource management will also be integrated in a complementary way, with innovation-oriented employee selection, recruitment, and training directed toward activities that are conducive to exploration and exploitation. In addition, as an intangible asset, entrepreneurial orientation is not automatically converted to innovation. This means that the enterprise must integrate employees' knowledge and skills and entrepreneurship concept through the human resources management system.

\section{Cultural Perspective}

Lee et al. [12] studied the strategic significance of innovative culture to organizational ambidexterity from the perspective of organizational culture. Although the implementation of exploration and utilization activities will bring about resource constraints and failure contradictions, but innovative culture can help firms obtain strategic flexibility to adapt to the environment, and further help firms adjust their organizational practices to adapt to these conflicts. In fact, research has confirmed that in the context of an innovative culture, organic organizations and empowered front-line managers are more passionate about conducting exploration and exploitation activities at the same time. In addition, an innovative culture promotes openness and inclusion to new ideas within an organization, which can also reduce the difficulty of facilitating exploration and exploitation. This means that managers tend to exploitation activities, but also extremely encourage exploration activities, and vice versa.

\section{Conclusion}

Organizational ambidexterity is an important strategy for firm's survival. Existing research has discovered that TMT and firm characteristics are two influencing factors of organizational ambidexterity. This paper mainly explore the antecedents of organizational ambidexterity from the perspective of TMT and firm characteristics. TMT behavioral integration balances strategic conflicts between exploration and exploitation of activities through creating a paradigmatic cognitive framework and processes. TMT diversification creates contradictory cognitive frameworks that can enhance the team's strategic planning capabilities and finally promote organizational ambidexterity. Except that, organizational ambidexterity can also be influenced by organizational foresight, learning capability and innovative culture. Innovative culture 
can help firms obtain strategic flexibility to adapt to the environment, and further help firms adjust their organizational practices to adapt to conflicts from ambidexterity.

\section{Acknowledgement}

This research was financially supported by the National Natural Science Foundation of China (71502064).

\section{References}

[1] W. K. Smith, M. L. Tushman, Managing strategic contradictions: A top management model for managing innovation streams, Organization Science. 16 (2005) 522-536.

[2] M. H. Lubatkin, Z. Simsek, Y. Ling, J. F. Veiga, Ambidexterity and performance in small-to medium-sized firms: The pivotal role of top management team behavioral integration, Journal of Management. 32 (2006) 646-672.

[3] A. Carmeli, M. Y. Halevi, How top management team behavioral integration and behavioral complexity enable organizational ambidexterity: The moderating role of contextual ambidexterity, The Leadership Quarterly. 20 (2009) 207-218.

[4] J. J. P. Jansen, G. George, F. A. J. Van den Bosch, H. W. Volberda, Senior team attributes and organizational ambidexterity: The moderating role of transformational leadership, Journal of Management Studies. 45 (2008) 982-1007.

[5] C. Li, Top management team diversity in fostering organizational ambidexterity: Examining TMT integration mechanisms, Innovation: Management, policy \& practice. 16 (2014) 303-322.

[6] L. A. Nemanicha, D. Verab, Transformational leadership and ambidexterity in the context of an acquisition, The Leadership Quarterly. 20 (2009) 19-33.

[7] Q. Cao, Z. Simsek, H. Zhang, Modelling the joint impact of the ceo and the tmt on organizational ambidexterity, Journal of Management Studies. 47 (2010) 1272-1296.

[8] A. Paliokaitè, N. Pačèsa, The relationship between organisational foresight and organisational ambidexterity, Technological Forecasting \& Social Change. 101 (2015) 165-181.

[9] W. Q. Judge, C. P. Blocker, Organizational capacity for change and strategic ambidexterity, European Journal of Marketing. 2008 (42) 915-926.

[10]H-E. Lin, E. F. McDonough, S-J. Lin, C. Y-Y. Lin, Managing the exploitation/exploration paradox: The role of a learning capability and innovation ambidexterity, Journal of Product Innovation Management. 30 (2013) 262-278.

[11] J. A. Zhang, F. Edgar, A. Geare, C. O'Kane. The interactive effects of entrepreneurial orientation and capability-based HRM on firm performance: The mediating role of innovation ambidexterity, Industrial Marketing Management. 59 (2016) 131-143.

[12] K. Lee, H-G. Woo, K. Joshi. Pro-innovation culture, ambidexterity and new product development performance: Polynomial regression and response surface analysis, European Management Journal. xxx (2016) 1-12. 